\title{
Tahap Pengetahuan Pelajar dalam Industri Sawit di Malaysia
}

\author{
Students' Knowledge of Malaysia Palm Oil Industry
}

\author{
Mohd Abdullah Jusoh ${ }^{\mathrm{a}}$, Ahmad Raflis Che Omar ${ }^{\mathrm{b}}$ \&Azhar Ahmad \\ ${ }^{a}$ Universiti Pendidikan Sultan Idris, Malaysia, mohd.abdullah@fpe.upsi.edu.my \\ b,c Universiti Kebangsaan Malaysia, Malaysia,raflis@ukm.edu.my,azhar@ukm.edu.my
}

\begin{abstract}
Abstrak
Kelapa Sawit merupakan antara komoditi penting di Malaysia. Ia memberi sumbangan yang besar kepada ekonomi negara. Kelapa sawit merupakan penyumbang utama kepada Keluaran Dalam Negara Kasar selain daripada petroleum dan getah. Namun begitu perkembangan sektor sawit di Malaysia menghadapi beberapa cabaran. Antaranya harga sawit yang kurang stabil, masalah kekurangan tenaga buruh, pengeluaran hasil sawit yang kurang konsisten dan juga minat generasi muda terhadap bidang penanaman sawit yang semakin berkurang. Oleh itu, generasi muda masa kini haruslah dipupuk supanya mempunyai tahap pengetahuan yang tinggi serta lebih cenderung untuk menceburkan diri dalam bidang ini. Selain itu, guru sebagai individu yang paling penting di sekolah haruslah memainkan peranan dalam menerapkan pendidikan mengenai sawit dalam kalangan pelajar di sekolah.
\end{abstract}

Kata kunci: pendidikan, kelapa sawit, pelajar, Malaysia

\begin{abstract}
Palm oil is among the most important commodity in Malaysia. It contributes significantly to the national economy. Palm oil is a major contributor to the Gross Domestic Product other than petroleum and rubber. However the development of the oil sector in Malaysia faces several challenges like less stable oil prices, labor shortages, production yields are less consistent and also the younger generation against the planting of diminishing returns. Therefore, the younger generation must be nurtured round to have higher knowledge and more likely to be involved in this field. In addition, individual teachers as the most important in the school should play a role in implementing education on palm among students in school.
\end{abstract}

Keywords: education, palm oil, student, Malaysia

\section{PENGENALAN}

Sektor pertanian adalah merupakan sektor yang terpenting bagi negara-negara membangun seperti malaysia. Ia merupakan satu sektor penting yang menjadi tumpuan dalam perdagangan dunia kerana merupakan pembekal makanan dan sumber bahan mentah yang utama kepada penduduk di seluruh dunia. Malah ia juga merupakan antara ciri terpenting yang membezakan status antara negara-negara membangun dan negara-negara maju. Sektor ini juga yang telah menyumbang kepada asas pembentukan ekonomi malaysia di dalam era selepas merdeka yang mana pada masa tersebut, majoriti penduduk tertumpu kepada aktiviti ekonomi berasaskan pertanian dan perlombongan. Di Malaysia, sektor pertanian telah menjadi nadi utama pertumbuhan ekonomi 
negara sejak merdeka hingga akhir tahun 1970-an. Antara tanaman yang penting adalah seperti koko, getah, sawah padi dan kelapa sawit. kelapa sawit adalah merupakan salah satu daripada pemacu utama sektor pertanian malaysia dengan penggunaan tanah pertanian negara sebanyak $71 \%$.

\section{INDUSTRI SAWIT DI MALAYSIA}

Penanaman kelapa sawit di Malaysia telah diperkenalkan oleh kerajaan bertujuan untuk membasmi kemiskinan dalam kalangan penduduk luar bandar. Pembangunan dalam industri kelapa sawit amat memberangsangkan dengan penekanan diberikan kepada penyelidikan bagi menghasilkan kaedah baru dalam teknologi penanaman, penghasilan benih yang berkualiti dan penghasilan produk-produk baru berasaskan kelapa sawit. Hasil daripada industri sawit dapat memberikan sumbangan yang signifikan kepada ekonomi negara. Berdasarkan Laporan Ekonomi 2015/2016, kelapa sawit telah memberikan sumbangan yang terbesar dalam sektor pertanian berbanding dengan tanaman yang lain iaitu sebanyak 32.4\% pada tahun 2014 serta 32.0\% pada tahun 2015 .

\section{Jadual 1: Sumbangan Kepada Sektor Pertanian}

\begin{tabular}{lcc}
\hline \multicolumn{1}{c}{ Pertanian } & \multicolumn{2}{c}{ Sumbangan kepada Pertanian (\%) } \\
\cline { 2 - 3 } & $\mathbf{2 0 1 0}$ & $\mathbf{2 0 1 5}$ \\
\hline Kelapa Sawit & 32.4 & 32.0 \\
Getah & 5.5 & 4.3 \\
Koko & 0.1 & 0.1 \\
Perhutanan dan Pembalakan & 19.8 & 17.4 \\
Pertanian dan lain-lain & 15.9 & 17.4 \\
Perikanan & 16.2 & 17.9 \\
Ternakan & 10.1 & 10.9 \\
\hline
\end{tabular}

Sumber: Laporan Ekonomi 2015/2016

Sejarah industri ini menjangkau lebih daripada 100 tahun di mana dalam tempoh tersebut, ia telah mencapai kejayaan yang mengagumkan. Dengan perkembangan yang berasaskan kepada beberapa kelebihan utama, industri ini akan kekal sebagai penyumbang utama kepada ekonomi negara untuk tempoh 10 tahun akan datang. Kelapa sawit adalah merupakan salah satu komoditi utama yang menyumbang dalam pendapatan yang menggalakkan kepada pekebun di luar bandar khususnya(Izzah Syazwany, Noraida \& Choy, 2015).

\section{CABARAN DALAM INDUSTRI SAWIT DI MALAYSIA}

Sebagaimana yang kita ketahui, kini Indonesia merupakan antara negara pengeluar utama minyak sawit dunia (Izzah Syazwany, Noraida \& Choy, 2015). Perkara ini menjadikan industri sawit Malaysia kini berada di persimpangan dan berhadapan dengan risiko kehilangan kelebihan daya saing kepada pengeluar lain di Asia, Afrika dan Amerika Selatan. Keadaan ini ditambah pula dengan masalah kekurangan tenaga kerja dan kos pengeluaran yang semakin meningkat. Hal ini menjadi semakin rumit apabila industri sawit di Malaysia masih lagi berintensifkan tenaga buruh. Ia menjadi cabaran utama kerana kos buruh yang semakin meningkat setiap tahun. Masalah kekurangan tenaga buruh ini secara tidak langsung membawa kepada pengambilan pekerja asing 
(Norsida \& Azimi, 2007). Hal ini kerana kekurangan belia yang berminat untuk bekerja dalam bidang pertanian dan hanya petani atau pekebun yang semakin tua sahaja yang masih meneruskan bidang usaha ini.

Kebanyakan negara maju mencatatkan tahap produktiviti buruh yang tinggi dan menghasilkan KDNK per kapita yang tinggi. KDNK per kapita yang tinggi membolehkan negara mencapai sumbangan pendapatan buruh yang tinggi kepada KDNK. Ini seterusnya membawa kepada gaji yang lebih tinggi bagi setiap pekerja. Namun, Malaysia mencatatkan sumbangan pendapatan buruh yang lebih tinggi tetapi tidak diiringi dengan peningkatan produktiviti yang lebih tinggi. Hal ini kerana, Malaysia terlibat dalam industri yang kurang produktif dan berintensifkan buruh disebabkan oleh keperluan jumlah pekerja berkemahiran rendah yang besar.

Selain itu, Malaysia sebagai sebuah negara yang berproduktiviti tinggi memerlukan tenaga kerja yang terpelajar iaitu dengan mempunyai kemahiran, pengetahuan dan bakat untuk membantu ekonomi mencapai kepelbagaian dan pertumbuhan. Tenaga buruh yang berkualiti tinggi membantu melonjakkan produktiviti buruh, pekerjaan dan kejayaan ekonomi jangka panjang. Oleh hal yang demikian, penyediaan modal insan yang serba boleh dan mantap dari segala aspek adalah sangat penting bagi melahirkan tenaga buruh yang berkualiti dan seterusnya dapat meningkatkan produktiviti industri sawit di Malaysia. Penyediaan modal insan yang berkualiti perlu untuk meningkatkan keupayaan negara dalam menghasilkan pelbagai sumber berasaskan pertanian serta dapat memenuhi permintaan di dalam negara di samping mengukuhkan lagi ekonomi dan kewangan sejagat. Penglibatan golongan belia dalam bidang pertanian seharusnya digerakkan agar bidang ini tidak lagi menjadi tumpuan golongan tua. Pendedahan tentang penting dan menariknya bidang pertanian perlulah dimulakan di sekolah rendah, menengah dan juga di pusat-pusat pengajian tinggi. Hal ini kerana tahap pengetahuan serta tahap kecenderungan pelajar terhadap sesuatu perkara memainkan peranan yang penting bagi menggalakan mereka untuk menceburi bidang tersebut dengan lebih mendalam. Di samping itu, guru juga bertindak sebagai medium yang sangat penting dalam menerapkan perasaan minat dalam diri pelajar untuk mempelajari dengan lebih lanjut tentang sesuatu perkara.

\section{Kesedaran Pelajar Terhadap Industri Sawit}

Mengikut Norasmah dan Salmah (2011), penghayatan tentang kefahaman terhadap sesuatu bidang akan mendorong individu untuk menceburi bidang kerjaya tersebut. Maklumat yang diperolehi akan menarik minat individu berkenaan untuk berkecimpung dalam bidang tersebut dan secara tidak langsung menggalakkan kecenderungan mereka untuk memilih kerjaya itu. Dalam kontek ini, faktor pengetahuan seperti maklumat yang lengkap akan memberi semangat kepada seseorang individu untuk melibatkan diri dalam pertanian khususnya sawit. Kajian Nurul Amizah (2015) pula mendapati bahawa pengetahuan luas pelajar dalam sesuatu bidang secara tidak langsung membantu mengetahui secara keseluruhan mengenai sesuatu perkara yang dipelajari. Kajian yang dijalankan oleh Nurul Hidayah, Haryati dan Wee (2013) mendapati pengetahuan para pelajar sangat penting dalam mendorong mereka mengenai kesedaran dalam sesuatu perkara. Hasil kajian telah menunjukkan terdapat tiga sumber utama yang telah dirujuk pelajar untuk mendapatkan pengetahuan mengenai sesuatu perkara iaitu sumber yang paling utama ialah televisyen, guru dan buku teks. Oleh itu, kita dapat nyatakan di sini bahawa terdapat faktor yang dapat mendorong meningkatkan pengetahuan pelajar dalam sesuatu perkara terutamanya dalam bidang pertanian sawit. 


\section{Tahap Kecenderungan Pelajar}

Sikap yang cenderung kepada sesuatu subjek akan meningkatkan motivasi pelajar untuk terus berusaha bagi meningkatkan prestasi dalam subjek tersebut. Menurut Abdul Halim dan Wan Mohamad (2006), sikap dan minat pelajar terhadap pelajaran bahasa Arab adalah penting dalam menentukan kejayaan mereka. Kajian terdahulu juga ada menyatakan bahawa pelajar yang mempunyai sikap yang positif terhadap Matematik akan mendapat keputusan yang baik dalam subjek ini (Papanastasiou, 2000). Abd Rahim (2001) mengatakan bahawa sikap memberi kesan yang khusus kepada tingkah laku, daya usaha, minat dan kesedaran. Sikap positif yang ditunjukkan pelajar ini dapat membantu mengatasi permasalahan yang dihadapi oleh pelajar.

Jadual 2 menunjukkan min, sisihan piawai dan interpretasi skor min mengenai tahap kecenderungan pelajar menceburi bidang pertanian sawit. Item yang mempunyai tahap skor min tertinggi ialah mengenai tumpuan yang lebih harus diberikan terhadap pengetahuan mengenai industri sawit untuk mendapatkan peluang pekerjaan pada masa hadapan 3.08 (sederhana) dengan sisihan piawai 1.48 manakala item yang mempunyai nilai min terendah ialah mengenai pelajar selalu ke perpustakaan untuk mendapatkan bahan bacaan tambahan mengenai industri sawit di Malaysia iaitu sebanyak 2.24 (rendah) dengan sisihan piawai 1.03. Min keseluruhan bagi item mengukur tahap kecenderungan pelajar menceburi bidang pertanian sawit adalah sebanyak 2.56 (Sederhana) serta nilai sisihan piawai keseluruhan ialah sebanyak 0.81.

Jadual 2: Tahap Kecenderungan Pelajar Menceburi Bidang Pertanian Sawit

\begin{tabular}{lccc}
\hline \multicolumn{1}{c}{ Pernyataan } & Min & $\begin{array}{c}\text { Tahap Skor } \\
\text { Min }\end{array}$ & $\begin{array}{c}\text { Sisihan } \\
\text { Piawai }\end{array}$ \\
\hline $\begin{array}{l}\text { Saya suka mempelajari dengan lebih lanjut mengenai industri sawit } \\
\text { yang terdapat di Malaysia. }\end{array}$ & 2.69 & Sederhana & 1.18 \\
$\begin{array}{l}\text { Saya suka bertanya kepada guru mengenai industri sawit yang terdapat } \\
\text { di Malaysia. }\end{array}$ & 2.51 & Sederhana & 1.01 \\
Saya selalu mencari maklumat berkaitan industri sawit di Malaysia. & 2.35 & Sederhana & 0.97 \\
$\begin{array}{l}\text { Saya selalu berbincang dengan rakan-rakan mengenai industri sawit di } \\
\text { Malaysia. }\end{array}$ & 2.3 & Sederhana & 0.98 \\
$\begin{array}{l}\text { Saya selalu ke perpustakaan untuk mendapatkan bahan bacaan } \\
\text { tambahan mengenai industri sawit di Malaysia. }\end{array}$ & 2.24 & Rendah & 1.03 \\
$\begin{array}{l}\text { Saya lebih berminat sekiranya pengajaran dan pembelajaran di dalam } \\
\text { kelas menekankan mengenai kepentingan industri sawit. }\end{array}$ & 2.54 & Sederhana & 1.08 \\
$\begin{array}{l}\text { Tumpuan yang lebih harus diberikan terhadap pengetahuan mengenai } \\
\text { industri sawit untuk mendapatkan peluang pekerjaan pada masa } \\
\text { hadapan. }\end{array}$ & 3.08 & Sederhana & 1.48 \\
$\begin{array}{l}\text { Saya sering merasa gembira apabila dapat mengetahui sesuatu yang } \\
\text { baru berkaitan dengan industri sawit. }\end{array}$ & 2.78 & Sederhana \\
$\begin{array}{l}\text { Saya akan merasa susah hati sekiranya saya ketinggalan dalam } \\
\text { mengetahui sesuatu yang baru berkaitan dengan industri sawit. }\end{array}$ & 2.54 & Sederhana & 1.14 \\
& & & \\
& & &
\end{tabular}


Mudah bagi saya untuk mengingati apa yang dibaca mengenai maklumat berkaitan dengan industri sawit.
2.56 Sederhana

1.1

Keseluruhan
$2.56 \quad$ Sederhana

0.81

Dapatan kajian yang dijalankan oleh Norasmah dan Salmah (2011) mendapati bahawa kecenderungan seseorang pelajar dalam sesuatu perkara dapat mempengaruhi mereka untuk mempamerkan tingkah laku pemilihan kerjaya yang lebih cerah dalam bidang yang diingini. Hal ini kerana, mereka memahami kerjaya yang ingin diceburi dan secara tidak langsung mengetahui risiko dan cabaran yang bakal ditempuhi. Perkara ini menunjukkan bahawa kecenderungan seseorang pelajar terhadap sesuatu perkara dapat mempengaruhi mereka untuk bertingkah laku secara positif terhadap pekerjaan yang diceburi. Para pelajar yang cenderung terhadap bidang pertanian sawit khususnya secara tidak langsung akan menyumbang hasil kerja yang lebih produktif dalam menjalankan kerja yang dilakukan dalam bidang tersebut.

\section{Peranan Guru}

Kajian oleh Mohammad Abdillah, Miss Asma dan Zamri (2014) menyatakan bahawa guru merupakan individu yang paling berpengaruh dalam meningkatkan pencapaian pelajar. Guru perlu melakukan beberapa perkara dalam membentuk sikap pelajar untuk meminati perkara yang diajar. Antaranya ialah guru perlu memupuk semangat dalam diri pelajar agar sentiasa membuat persediaan sebelum bermulanya kelas, sentiasa mengulangkaji subjek yang diajar dan sentiasa mencari bahan-bahan pelajaran yang berkaitan. Oleh yang demikian, melalui kajian ini kita dapat nyatakan bahawa terdapat pelbagai cara yang dapat dilakukan oleh guru dalam meningkatkan minat pelajar untuk mendalami dengan lebih mendalam berkaitan bidang pertanian sawit di sekolah.

Jadual 3 menunjukkan taburan min, sisihan piawai dan interpretasi skor sikap para guru dalam menerapkan model pendidikan sawit dalam kalangan pelajar di sekolah. Item mengenai "guru dapat menerangkan dengan baik mengenai industri sawit di Malaysia" mencapai tahap skor min yang tinggi iaitu sebanyak 2.9 (sederhana) dengan sisihan piawai 1.16 manakala item "guru selalu meminta pelajar memberikan contoh tentang apa yang dibaca berkaitan dengan industri sawit" mencapai nilai min yang terendah iaitu sebanyak 2.64 (sederhana) dengan sisihan piawai 1.09. Nilai min keseluruhan bagi item-item untuk mengukur sikap guru dalam menerapkan model pendidikan sawit dalam kalangan pelajar di sekolah ialah sebanyak 2.73 (sederhana) serta nilai sisihan piawai keseluruhan ialah sebanyak 0.88 .

\section{Jadual 3: Peranan Guru}

\begin{tabular}{|c|c|c|c|}
\hline Pernyataan & Min & $\begin{array}{c}\text { Tahap Skor } \\
\text { Min }\end{array}$ & $\begin{array}{l}\text { Sisihan } \\
\text { Piawai }\end{array}$ \\
\hline $\begin{array}{l}\text { Guru memberikan pendedahan kepada saya mengenai industri sawit } \\
\text { di Malaysia. }\end{array}$ & 2.69 & Sederhana & 1.15 \\
\hline $\begin{array}{l}\text { Guru mendedahkan kepada saya peluang-peluang kerjaya yang } \\
\text { terdapat dalam industri sawit. }\end{array}$ & 2.7 & Sederhana & 1.07 \\
\hline $\begin{array}{l}\text { Guru dapat menerangkan dengan baik mengenai industri sawit di } \\
\text { Malaysia. }\end{array}$ & 2.9 & Sederhana & 1.16 \\
\hline
\end{tabular}




\begin{tabular}{lccc}
\hline $\begin{array}{l}\text { Guru selalu meminta pelajar memberikan contoh tentang apa yang } \\
\text { dibaca berkaitan dengan industri sawit. }\end{array}$ & 2.64 & Sederhana & 1.09 \\
$\begin{array}{l}\text { Guru memberikan contoh dan pendapat berkaitan dengan industri } \\
\text { sawit semasa sesi pembelajaran berlangsung. }\end{array}$ & 2.76 & Sederhana & 1.09 \\
$\begin{array}{l}\text { Guru menggunakan pelbagai kaedah pengajaran untuk } \\
\text { menambahkan pengetahuan pelajar berkaitan industri sawit di }\end{array}$ & 2.74 & Sederhana & 1.08 \\
Malaysia. & & \\
$\begin{array}{l}\text { Guru sering menceritakan kepada pelajar tentang industri sawit } \\
\text { yang terdapat di luar negara. }\end{array}$ & 2.68 & Sederhana & 1.08 \\
$\begin{array}{l}\text { Guru dapat menerangkan dengan jelas cara pengendalian peralatan } \\
\text { dan mesin yang digunakan dalam industri sawit. }\end{array}$ & 2.73 & Sederhana & 1.13 \\
$\quad$ Keseluruhan & 2.73 & Sederhana & 0.88 \\
\hline
\end{tabular}

Ahmad, Kamarul dan Khairunnisa (2016) mendapati terdapat hubungan yang postif antara guru dengan pelajar dan menyatakan bahawa hubungan antara guru dengan pelajar adalah penting tanpa mengira umur dan sebagainya. Guru seharusnya mengetahui latar belakang pelajar sebelum pengajaran dan pembelajaran dijalankan kerana setiap pelajar mempunyai sikap dan cara belajar yang tersendiri. Hasil kajian Ahmad Rizal, Nurul Akmar dan Saifullizam (2005) mendapati pengajaran guru adalah merupakan salah satu faktor yang paling mempengaruhi penguasaan pelajar dalam sesuatu mata pelajaran. Guru seharusnya memantau iklim sekolah seperti kemudahan yang disediakan dalam kelas bagi menjamin keperluan yang mencukupi untuk pelajar menimba ilmu yang dipelajari. Oleh itu, dapat kita katakan di sini bahawa guru mestilah memastikan kemudahan yang mencukupi seperti bahan bacaan dan sebagainya di dalam kelas bagi memastikan pengetahuan berkaitan industri pertanian sawit dapat diterima baik oleh pelajar di sekolah.

\section{CADANGAN PROGRAM KEPADA PELAJAR}

Berdasarkan kajian-kajian terdahulu, sememangnya terbukti bahawa industri sawit sangat penting bagi menjana sektor pertanian di Malaysia.Oleh yang demikian, perkara ini seharusnya dititikberatkan dan langkah-langkah yang sewajarnya perlu dilakukan bagi meningkatkan penglibatan masyarakat Malaysia dalam industri ini. Sebagai persediaan bagi peringkat awal, pelbagai program perlulah dilaksanakan untuk memberi pendedahan kepada pelajar tentang kepentingan industri sawit kepada negara. Antaranya ialah dengan memberi kesedaran kepada generasi muda tentang peluang kerjaya yang terdapat dalam bidang ini.Selain itu, bagi menggalakkan lagi generasi muda untuk menceburi bidang ini, industri sawit perlu diberi nilai tambah. Hal ini kerana, ia berupaya meningkatkan pendapatan dan akhirnya secara tidak langsung dapat menarik minat lebih ramai generasi muda untuk menceburi bidang ini. Sebagaimana yang kita ketahui, generasi muda adalah generasi yang produktif serta berupaya memberi sumbangan tenaga dan idea yang inovatif ke arah menyelesaikan cabaran utama sektor sawit yang berintensifkan buruh. Dengan usaha awal untuk memberi kesedaran kepada generasi muda melalui kurikulum samadasecara langsung atau tidak langsung serta ko-kurikulum seperti lawatan ke ladang sawit, kilang-kilang dan industri hiliran yang berkaitan, kuiz, pertandingan reka cipta dan inovasi khusus untuk bidang sawit,iainya berupaya menarik generasi muda menjadikan industri 
pertanian khususnya sawit sebagai kerjaya pilihan. Di samping itu, bagi menerapkan lagi rasa minat dalam diri pelajar mengenai industri ini, pihak yang bertanggungjawab dalam pendidikan haruslah menitikberatkan aspek kurikulum di sekolah. Kurikulum pendidikan di sekolah perlulah membincangkan secara khusus mengenai industri sawit di Malaysia. Contohnya ialah dengan memasukkan elemen mengenai industri sawit di Malaysia dalam mata pelajaran Sains Pertanian.

Dapatan kajian ini menunjukkan bahawa terdapat hubungan antara tahap pengetahuan pelajar terhadap industri sawit dengan tahap kecenderungan pelajar menceburi bidang pertanian sawit serta hubungan antara hubungan di antara sikap guru dengan tahap kecenderungan pelajar menceburi bidang pertanian sawit. Implikasi daripada kajian ini menunjukkan bahawa para pelajar seharusnya didedahkan dengan pengetahuan berkaita dengan industri sait di Malaysia. Perkara ini adalah bertujuan untuk menaikkan semangat serta minat mereka dalam meneroka dengan lebih mendalam mengenai industri sawit di Malaysia.

Selain itu, pendidikan di sekolah pula seharusnya mewujudkan satu model pendidikan sawit. Langkah ini adalah bertujuan untuk memberi pengetahuan kepada pelajar mengenai kebaikan serta sumbangan industri sawit di negara ini. Ia juga secara tdak langsung dapat menarik minat pelajar untuk menceburkan diri dalam indusri sawit. Antara perkara yang dapat diterapkan d sekolah ialah dengan memperkenalkan mata pelajaran berkaitan dengan penanaman sawit di Malaysia atau memasukkan topik berkaitan industri sawit di dalam mata pelajaran tertentu.

Di samping itu, guru memainkan peranan yang sangat penting dalam menjayakan model pendidikan sawit di sekolah. Para guru mestilah memerikan pendedahan yang sewajarnya kepada para pelajar mengenai industri penanaman sawit di Malaysia. Mereka seharusnya memberikan maklumat mengenai pelbagai bidang kerjaya yang dapat diceburi melalui industri ini. Hal ini secara tidak langsung membuka minda pelajar mengenai pentingnya untuk melibatkan diri alam industri ini.

\section{KESIMPULAN}

Guru memainkan peranan yang sangat penting dalam mempengaruhi para pelajar untuk menceburkan diri dalam industri penanaman sawit di Malaysia. Pelajar kurang mendapat pendedahan pengetahuan mengenai industri sawit dan secara tidak langsung mempengaruhi mereka untuk menceburkan diri dalam bidang tersebut. Guru sememangnya memainkan peranan yang penting dalam meningkatkan minat pelajar untuk mendalami dan menguasai bidang perindustrian sawit melalui pelbagai cara. Antaranya ialah dengan menjadikan corak pengajaran dan pembelajaran di dalam kelas lebih menarik serta menyampaikan pengetahuan mengenai industri secara lebih interaktif. Situasi ini secara tidak langsung dapat meningkatkan rasa minat dan ingin tahu dalam kalangan pelajar tehadap perkara yang diajar. Pelajar yang mendapat galakan daripada guru akan lebih bermotivasi untuk mendalami dan meneruskan minat mereka untuk mengetahui dengan lebih lanjut mengenai bidang tersebut. Kesimpulannya, industri sawit memainkan peranan yang penting dalam pembangunan dan pertumbuhan ekonomi Malaysia.Oleh itu, industri ini perlu dimajukan bagi menjamin kestabilan ekonomi negara berada pada tahap yang baik. Setiap pihak mestilah memainkan peranan dalam memastikan generasi muda yang bertindak sebagai faktor penentu ekonomi pada masa hadapan untuk menceburkan diri dalam bidang ini. 
Mereka mestilah dididik dan diterapkan dengan pengetahuan dalam industri sawit sejak di bangku sekolah lagi.

\section{RUJUKAN}

Abdul Halim \& Wan Mohamad. (2006). Antara minat dan sikap pelajar terhadap bahasa Arab: satu kajian ke atas pelajar Bacelor Bahasa Arab di IPTA Malaysia. Wacana Pendidikan Islam (Siri 5). Pendidikan Islam dan Bahasa Arab Pemangkin Peradaban Ummah. Fakulti Pendidikan Universiti Kebangsaan Malaysia. Bangi.

Abd.Rahim. (2001). Nilai-nilai murni dalam pendidikan. Kuala Lumpur: Cergas (M) Sdn. Bhd.

Abdul Rasid A. R., Nurul Ikhwan R., Ahmad E., Jamaludin H. \& Mohd Zaid M. (2009). Pengaruh subjek pertanian dalam membina minat pelajar terhadap kerjaya dalam bidang pertanian: kajian kes di sekolah menengah teknik. Seminar Kebangsaan Pendidikan Teknik dan Vokasional Kali Ke-3.

Ahmad, F. M. N., Kamarul, A. \& Khairunnisa, A. S. (2016). Pembinaan hubungan di antara guru dengan pelajar. Technical and Social Science Journal.138-148.

Ahmad Rizal M., Nurul Akmar K. \& Saifullizam P. (2005). Faktor-faktor yang mempengaruhi pencapaian pelajar dalam menguasai mata pelajaran kejuruteraan di politeknik-politeknik Kementerian Pengajian Tinggi Malaysia. Prosiding Seminar Pendidikan JPPG 2005.

AinonMohd. (2003). Bagaimana hendak mendorong semangat Kerja. Bentong: PTS Publications \& Distributor Sdn. Bhd.

Akhiar P. \& Shamsina S. (2011). Pengantar penyelidikan tindakan dalam penyelidikan pendidikan. Selangor. Penerbitan Multimedia Sdn. Bhd.

Carbonaro, W. (2005).Tracking, students' effort, and academic achievement. Sociology of Education, 78, 27-49.

Cropley, A. J. 1992. More ways than one: Fostering creativity. New Jersey: Ablex Publishing Corporation.

Darling-Hammond, L. (2000). Teacher quality and students' achievement. Diperoleh pada Mac 15, 2016 daripada http://epaa.asu.edu/epaa/v8nl.

Fredriksen, K \& Rhodes, J. (2004). The role of teacher relationships in the lives of students. Diperoleh pada Februari 20, 2016 daripada http://www.interscience.wiley.com/journal/109614153/abstract

Izzah Syazwany M. N., Noraida A. R. \& Choy E. A. (2015). Faktor pemilihan minyak sawit dalam kalangan pengguna: kajian empirikal di Putrajaya, Malaysia. Malaysian Journal of Society and Space, 11(8), 6677.

Maziah, C. Y. (2005). Kajian kecenderungan pemilihan kerjaya di kalangan siswazah. Jurnal Pengurusan Awam. 4 (11).36-46.

Mohamad Abdillah, R. \& Haleefa, M. (2010). Faktor-faktor kelemahan yang mempengaruhi pencapaian cemerlang pelajar dalam mata pelajaran reka cipta di tiga buah sekolah menengah akademik di daerah Johor Bahru.1-12.

Mohamad Johdi, S., Mazliza, K. \& Henry, J. F. (2012). Kajian terhadap faktor-faktor mempengaruhi pencapaian pelajar dalam penilaian menengah rendah di Sabah. Labuan International Conference on Educational Research-LICER 2012.

Mohamad Najib A. G. (2003). Reka bentuk tinjauan soal selidik pendidikan. Skudai: Universiti Teknologi Malaysia.

Mohammad Abdillah, S., Miss Asma, B. \&Zamri, A. (2014). Hubungan antara kecenderungan minat pelajar dalam Bahasa Arab dengan kualiti diri guru bahasa Arab MRSM Ulul Albab, Kota Putra. Prosiding Seminar Pengajaran \& Pembelajaran Bahasa Arab 2014.1-8.

Mohd.Fadzli, I. \& Mohd. Sukki, O. (2012). Faktor-faktor yang mempengaruhi pencapaian pelajar dalam pengajaran \& pembelajaran Bahasa Arab: satu tinjauan di SMAP Kajang Persidangan Kebangsaan Pengajaran dan Pembelajaran Bahasa Arab 2012 (PKEBAR'12).173-189.

Mohd.Majid K. (2009). Kaedah penyelidikan pendidikan. Kuala Lumpur. Dewan Bahasa dan Pustaka. 
Noor Erma, A. \& Leong, K. E. (2014). Hubungan antara sikap, minat, pengajaran guru dan pengaruh rakan sebaya terhadap pencapaian matematik tambahan tingkatan 4. Jurnal Kurikulum \& Pengajaran Asia Pasifik. 2(1). 1-10

Noraini O. (2008). Faktor-faktor yang mempengaruhi pencapaian pelajar dalam mata pelajaran pendidikan Islam tingkatan lima. Kota Samarahan. Institut Pendidikan Guru Kampus Tun Abdul Razak

Norasmah O., \& Salmah I. (2011). Kecenderungan terhadap pemilihan kerjaya keusahawanan mengikut persepsi peserta skim usahawan siswa. Jurnal Teknologi 56, 47-63.

Norani, M. N. \& Norisham, A. R. (2011). Kecenderungan pelajar-pelajar Institut Kemahiran Mara (IKM) Johor Bahru terhadap bidang keusahawanan. Journal of Science \& Mathematics Education.1-9.

Norsida, M., \&Azimi, H. (2007). Keperluan program pendidikan pertanian di kalangan belia tani di kawasan luar bandar. Serdang, Selangor: Universiti Putra Malaysia.

Nur Eliza M., Siti Hajar S. \& Siti Mariam S. (2014). Tahap kompetensi teknologi maklumat dan komunikasi (ICT) dalam kalangan pelajar Jabatan Perdagangan Politeknik Tuanku Sultanah Bahiyah. Diperoleh pada Februari 11, 2016 daripada http://ecrim.ptsb.edu.my/file/20141106091611.pdf

Nurul Hidayah L. A., Haryati S. \& Wee S. T. (2013). Pengetahuan murid dan perkaitan ibu bapa terhadap kesedaran alam sekitar: satu kajian awal. Jurnal Teknologi, 64(1), 51-57.

Papanastasiou, C. (2000). Effects of attitudes and beliefs on Mathematics Achievement. Studies in Educational Evaluation, 26 (1) 27-42.

O'Donnell, M. \& Preedy, M. (2001). Taking action to improve students' attitudes and motivation. Management in Education, 15(5), 25.

Rodiah A. (2008). Pengajaran guru, persekitaran pembelajaran dan sikap murid dalam pembelajaran KOMSAS. Tesis Program Sarjana Pendidikan (Tidak diterbitkan). Pulau Pinang, Universiti Sains Malaysia.

Rohani A., Hazri J. \& Nordin A. R. (2010). Hubungan guru-pelajar dan kaitannya dengan komitmen belajar pelajar: adakah guru berkualiti menghasilkan perbezaan pembelajaran antara jantina pelajar. Jurnal Pendidikan Malaysia, 35(2), 61-69.

Salleh. (2003). Pemikiran professional keguruan terhadap kurikulum dan pengajaran. Dibentangkan di Seminar Pendidikan MPBL.

Sohair A. M. S. (1990). Satu tinjauan tentang masalah-masalah pengajaran mata pelajaran bahasa arab di sekolah-sekolah menengah agama di Malaysia. Tesis Sarjana. Bangi: Universiti Kebangsaan Malaysia.

Trembley S., Ross N., Berthelot J.M., (1999). The relationship between enviromental quality of school facilities and student performance. Enviromental International, 12, 147-159.

Wan Azura W. A. \& Lubna A. R. (2013). Pembelajaran bahasa Arab di Universiti Sains Islam Malaysia (USIM): tinjauan kecenderungan pelajar. 1-13.

Yufiza, M.Y.\& Norhayati, O. (2013). Kecenderungan kerjaya keusahawaan dalam kalangan pelajar Perhebat di kolej komuniti. Seminar HEP Kebangsaan 2013, Kolej Komuniti Kementerian Pendidikan Malaysia: 'Lestari Kegemilangan Pelajar'. 185-196.

Zainudin \& Nor Hisham. (2010). Pendekatan pengajaran guru dan kesannya terhadap pencapaian pelajar dalam mata pelajaran kemahiran hidup di Sekolah Menengah Kebangsaan Senai, Johor. Skudai: Universiti Teknologi Malaysia.

Zainudin A. B., Meor Ibrahim K. \& Yang T. M.,( 2009). Pengaruh sikap, minat, pengajaran guru, dan rakan sebaya terhadap pencapaian matematik pelajar. Skudai: UniversitiTeknologi Malaysia. 